\title{
HUBUNGAN KEMANDIRIAN BELAJAR DAN HASIL BELAJAR MAHASISWA PADA MATA KULIAH KALKULUS LANJUT
}

\author{
Ari Suningsih', Aulia Kesuma Putri² \\ ${ }^{1,2}$ Program Studi Pendidikan Matematika, STKIP Muhammadiyah Pringsewu Lampung \\ Email : ${ }^{1}$ ari.suningsih@ @stkipmpringsewu-lpg.ac.id \\ ${ }^{2}$ kesumaputri_aulia@yahoo.com
}

\begin{abstract}
The result of observation at STKIP Muhammadiyah Pringsewu Lampung in the last 5 academic year, it is found that the result of student learning in Advanced Calculus Course is still a lot of students who get the value of C, D and E is 397 $(41,84 \%)$ students. This shows that the students' learning outcomes are still low. Allegedly low student learning outcomes due to the independence of learning. This is seen when given the task most students rarely do their own tasks. With regard to the matter then the formulation of the problem in this study is whether there is a relationship of independence learning and results learning outcomes in Advanced Calculus Courses, while the purpose of this study is to determine the relationship of learning independence and student learning outcomes. Sampling technique used in this research is Simple Random Sampling. To obtain data independence of student learning instrument used in the form of a questionnaire and to obtain data learning results using data documentation of learning outcomes. This research is a quantitative research with data analysis technique is Pearson Product Moment Correlation analysis. Based on data analysis, the result of the research shows that there is a strong correlation between student's learning independence on learning result in Advanced Calculus Course, this is indicated by the magnitude of correlation coefficient 0.566. This proves that learning independence contributes $32,04 \%$
\end{abstract}

Keywords: Independence Learning, Results learning

\section{A. PENDAHULUAN}

Matematika merupakan salah satu ilmu yang diajarkan disemua jenjang pendidikan, sebagai ilmu dasar matematika memiliki karakteristik sebagai ilmu deduktif, abstrak, terstruktur dan konsisten untuk membekali mahasiswa dengan kemampuan berpikir logis, sistematis, analitis, kritis dan kreatif serta kemampuan bekerja sama. Belajar matematika akan menumbuhkembangkan kemampuan learning to learn atau pembelajaran untuk belajar, yang berarti dalam belajar tidak hanya berorientasi pada daya serap mahasiswa tetapi juga berorientasi pada proses pembelajaran, serta menumbuhkembangkan kemampuan bernalar yang dipunyai mahasiswa

Berpikir, memecahkan masalah dan menghasilkan sesuatu yang baru adalah kegiatan yang kompleks dan berhubungan erat satu sama lain. Kemampuan dalam berpikir dapat menghasilkan gagasangagasan baru bagi seseorang, dalam me- 
ngembangkan intelektual untuk memecahkan masalah. Kemampuan berpikir sangat dibutuhkan dalam pemecahan masalah atau pencarian solusi. Pengembangan kemampuan berpikir merupakan penyatuan beberapa bagian pengembangan kemampuan, seperti pengamatan (observasi), analisis, penalaran, penilaian, pengambilan keputusan, dan penyampaian informasi sesuai dengan bukti dan fakta. Semakin baik pengembangan kemampuan-kemampuan ini, maka kita akan semakin dapat mengatasi masalahmasalah dengan hasil yang memuaskan.

Berdasarkan observasi di STKIP Muhammadiyah Pringsewu Lampung, diperoleh bahwa hasil belajar mahasiswa pada Mata Kuliah Kalkulus Lanjut sangat memprihatinkan dan bahkan banyak mahasiswa yang tidak lulus mata kuliah tersebut. Berikut ini data hasil belajar mahasiswa pada Mata Kuliah Kalkulus Lanjut disajikan pada Tabel 1 sebagai berikut.

\section{Tabel. 1}

\section{Hasil Belajar Mahasiswa pada Mata Kuliah Kalkulus Lanjut}

\begin{tabular}{|c|c|c|c|c|c|c|c|}
\hline \multirow{2}{*}{$\mathrm{N}_{0}$} & \multirow{2}{*}{$\begin{array}{c}\text { Tahun } \\
\text { Akademik }\end{array}$} & \multirow{2}{*}{$\begin{array}{c}\text { Jumlah } \\
\text { Mahasiswa }\end{array}$} & \multicolumn{5}{|c|}{ Nilai Akhir } \\
\hline & & & $\mathrm{A}$ & $B$ & $\mathrm{C}$ & D & $\mathrm{E}$ \\
\hline $\mathrm{A}$ & \multicolumn{7}{|c|}{ Kalkulus Lanjut } \\
\hline 1 & 2011-2012 & 297 & 21 & 57 & 178 & 41 & 0 \\
\hline 2 & 2012-2013 & 242 & 38 & 117 & 86 & 1 & 0 \\
\hline 3 & 2013-2014 & 163 & 44 & 42 & 49 & 16 & 12 \\
\hline 4 & 2014-2015 & 67 & 25 & 42 & 0 & 0 & 0 \\
\hline 5 & 2015-2016 & 180 & 124 & 42 & 12 & 0 & 2 \\
\hline \multicolumn{2}{|c|}{ Total } & 949 & 252 & 300 & 325 & 58 & 14 \\
\hline \multicolumn{2}{|c|}{ Persentase } & $100 \%$ & $26,55 \%$ & $31,61 \%$ & $\begin{array}{c}34,25 \\
\%\end{array}$ & $6,11 \%$ & $\begin{array}{c}1,48 \\
\%\end{array}$ \\
\hline
\end{tabular}

Sumber: BAAK STKIP Muhammadivah Pringservu Lampung
Tabel 1 memperlihatkan bahwa rata-rata persentase kelulusan mahasiswa pada Mata Kuliah Kalkulus Lanjut diperoleh bahwa dari 949 mahasiswa diperoleh bahwa sebanyak $252(26,55 \%)$ mahasiswa mendapatkan nilai A, sebanyak $300(31,61 \%)$ mahasiswa mendapatkan nilai $\mathrm{B}$, sebanyak $325(34,25 \%)$ mahasiswa mendapatkan nilai C, sebanyak $58(6,11 \%)$ mahasiswa mendapatkan nilai D dan sebanyak $14(1,48 \%)$ mahasiswa memperoleh nilai E.

Berdasarkan data di atas diduga rendahnya hasil belajar pada Mata Kuliah Kalkulus Lanjut dikarenakan kurangnya kemandirian belajar. Hal ini terlihat pada saat diberikan tugas kebanyakan mahasiswa jarang mengerjakan sendiri tugasnya selain itu mahasiswa tersebut lebih sering menunggu hasil jawaban dari teman lainnya tanpa mau tau dari mana hasil jawabannya dan setiap akan ujian mahasiswa tersebut sudah membuat catatan kecil untuk menyontek. Hal tersebut menggambarkan bahwa kurangnya inisiatif dalam belajar, tidak memiliki target dan tujuan dalam belajar serta tidak memiliki konsep diri. Dengan demikian maka terlihat bahwa rendahnya hasil belajar dipengaruhi oleh kemandirian. Hal tersebut sependapat dengan Soewandi yang dikutip Ali dan Asrori (2011:107) yang menyatakan bahwa dalam konteks proses pembelajaran, gejala yang tampak adalah kurang mandiri dalam 
belajar yang berakibat pada gangguan mental setelah memasuki perguruan tinggi.

Hargis (dalam Sumarmo, 2012:5) melaporkan bahwa siswa yang memiliki kemandirian belajar yang tinggi cenderung belajar lebih baik dalam pengawasannya sendiri, mampu memantau, mengawasi, dan mengatur belajarnya secara efektif, menyelesaikan waktu dalam menyelesaikan tugasnya, dan mengatur belajar dan waktu secara efisien. Kemandirian belajar dikatakan penting, karena salah satu aspek perilaku yang dapat membuat sekolah sukses adalah kemandirian belajar siswa (Blair, 2003:2; Vrieling, 2012:103). Sejalan dengan pendapat Boekaerts, dkk. (dalam Azizah, dkk., 2014:156) bahwa keberhasilan dalam bidang pendidikan didasarkan pada tingkat kemandirian seseorang, motivasi, dan kreativitas.

Berdasarkan permasalahan di atas kemandirian belajar mahasiswa perlu dikembangkan karena kemandirian belajar mahasiswa merupakan hal yang turut menentukan berhasilnya pengimplementasian pembelajaran dan turut menentukan pencapaian hasil belajar mahasiswa, hal ini cukup beralasan karena pembelajaran yang menciptakan situasi efektif, yaitu mengatur, menyusun dan memotivasi sehingga tujuan tercapai secara optimal. Menurut Wolters, Pintrich, dan Karabenick yang dikutip Ratnaningsih (2007:38) bahwa kemandirian belajar adalah suatu proses konstruktif dan aktif dimana peserta didik menentukan tujuan dalam belajar, dan mencoba untuk memonitor, mengatur, dan mengendalikan kognisi, motivasi, dan perilaku dengan dibimbing dan dibatasi oleh tujuan dan karakteristik kontekstual dalam lingkung-an. Memperkuat hal tersebut Sugandi (2013:149) mengutarakan tentang indikator dalam kemandirian belajar sebagai berikut: 1) inisiatif belajar; 2) mendiagnosa kebutuhan belajar; 3) menetapkan target dan tujuan belajar; 4) memonitor, mengatur dan mengontrol; 5) memandang kesulitan sebagai tantangan; 6) memanfaatkan dan mencari sumber yang relevan; 7) memilih dan menerapkan strategi belajar; 8) mengevaluasi proses dan hasil belajar; dan 9) self eficacy (konsep diri). Dalam Proses pembelajaran yang dilakukan tentunya ada capaian yang dihasilkan dalam hal ini adalah hasil belajar. Dimyati dan Mudjiono (2009:3) menyatakan bahwa hasil belajar merupakan hasil dari suatu interaksi tindak belajar dan tindak mengajar. Dari sisi dosen, tindak mengajar diakhiri dengan proses evaluasi hasil belajar. Dari sisi mahasiswa, hasil belajar merupakan berakhirnya pangkal dan puncak proses belajar.

Menurut Suprijono (2011:5) bahwa hasil belajar adalah pola-pola perbuatan, nilai-nilai, pengertian-pengertian, sikapsikap, apresiasi dan keterampilan. Dengan demikian kemandirian belajar diperlukan 
mahasiswa untuk lebih aktif dalam mencari konsep agar lebih luas yang didorong oleh motivasi untuk menguasai sesuatu kompetensi, dan dibangun dengan bekal pengetahuan atau kompetensi yang telah dimiliki maka kemandirian belajar perlu dikembangkan agar konsep diperoleh lebih banyak sehingga penelitian ini bertujuan untuk mengetahui hubungan antara kemandirian belajar dan hasil belajar mahasiswa pada Mata Kuliah Kalkulus Lanjut

\section{B. METODE PENELITIAN}

Penelitian ini termasuk penelitian assosiatif (hubungan) dan variabel dalam penelitian ini ada dua yaitu variabel bebas dan variabel terikat. Variabel bebas (X) dalam penelitian ini yaitu kemandirian belajar mahasiswa sedangkan variabel terikat (Y) dalam penelitian ini yaitu hasil belajar mahasiswa semester 5 pada Mata Kuliah Kalkulus Lanjut Tahun Akademik 2016-2017. Populasi yang digunakan dalam penelitian ini adalah seluruh Mahasiswa Semester 5 yang mengikuti Mata Kuliah Kalkulus Lanjut Program Studi Pendidikan Matematika Sekolah Tinggi Keguruan dan Ilmu Pendidikan (STKIP) Muhammadiyah Pringsewu Lampung Tahun Akademik 2016-2017 yang berjumlah 45 .

Teknik sampling yang digunakan adalah teknik Simple Random Sampling. Menurut Riduwan (2009:124) bahwa Simple
Random Sampling adalah pengambilan sampel dari anggota populasi dengan menggunakan acak tanpa memperhatikan strata (tingkatan) dalam anggota populasi tersebut. Selanjutnya Menurut Roscoe yang dikutip Sugiono (2010:103) menyatakan bahwa ukuran sampel yang layak dalam penelitian adalah 30 s.d 500. Berdasarkan teknik pengambilan sampel tersebut, terpilih 30 mahasiswa sebagai sampel yang mengikuti Mata Kuliah Kalkulus Lanjut. Untuk memperoleh data penelitian, digunakan instrumen berupa angket kemandirian belajar dan dokumentasi hasil belajar. Instrumen angket yang dimaksud adalah sebuah pertanyaan tertulis yang berjumlah 60 item. Kategori penskoran untuk alternatif jawaban angket kemandiri-an belajar diadopsi dari skala likert dari Riduwan (2009:87). Angket yang digunakan adalah angket tertutup yaitu angket yang disajikan dalam bentuk daftar pertanyaan yang memiliki alternatif jawaban sehingga responden diminta untuk mengisi jawaban yang sesuai dengan keadaan dirinya sendiri dengan cara memberi tanda (X). Sebelum Instrumen digunakan untuk pengambilan data penelitian, terlebih dahulu dilakukan pengembangan instrumen untuk mengetahui instrumen tersebut layak atau tidak. Syarat instrumen yang layak digunakan adalah instrumen harus valid dan reliabel. Selanjutnya analisis data yang digunakan untuk melakukan pengujian 
hipotesis dan menjawab rumusan masalah yaitu menggunakan Korelasi Pearson Product Moment, namun sebelum dilakukan uji analisis maka terlebih dahulu diuji bahwa data berdistribusi normal.

\section{HASIL DAN PEMBAHASAN}

Berdasarkan hasil analisis dalam penelitian ini diperoleh data skor angket kemandirian belajar mahasiswa dan data dokumentasi hasil belajar mahasiswa yag mengikuti Mata Kuliah Kalkulus Lanjut pada Tahun Akademik 2016-2017, dapat dilihat pada Tabel 2 berikut.

Tabel. 2

Data Skor Angket Kemandirizan Belajar Malasisiswa dan Data Hasil Belajar Mahasisiswa Pada Mata Kulliah Kalkulus Lanjut

\begin{tabular}{|c|c|c|c|c|c|c|c|}
\hline No & \begin{tabular}{|l|} 
Nama \\
Mahasisstra \\
\end{tabular} & \begin{tabular}{|l|} 
Skor \\
Total \\
\end{tabular} & \begin{tabular}{|l|} 
Hasil \\
Belajar \\
\end{tabular} & $\mathrm{N}_{0}$ & Nama Mahasiswra & \begin{tabular}{|l|} 
Skor \\
Total \\
\end{tabular} & \begin{tabular}{|l|} 
Hasil \\
Belajar
\end{tabular} \\
\hline 1 & PandhuE.S & 237 & 76 & 16 & Arita Sarí & 211 & 79 \\
\hline 2 & Tri Handavani & 209 & 70 & 17 & Chindy Erda Sari & 207 & 78 \\
\hline 3 & Dwi Rekawati & 214 & 74 & 18 & Rizki Dwi Ananda & 199 & 72 \\
\hline 4 & IffahN N H & 207 & 72 & 19 & Dian Reigina M & 245 & 83 \\
\hline 5 & Leni Budi Arti & 201 & 78 & 20 & MeiHeelinda & 232 & 91 \\
\hline 6 & SitinNurwagivah & 203 & 74 & 21 & Lidia Elicia Utami & 233 & 74 \\
\hline 7 & Yunil Indrivanil & 219 & 80 & 22 & Jaka Dwihendra & 221 & 86 \\
\hline 8 & Mitha Liviani & 226 & 83 & 23 & RestuDwi Ariani & 204 & 76 \\
\hline 9 & DestiAnitasari & 197 & 63 & 24 & SititRugavah & 230 & 91 \\
\hline 10 & Elly Apritia & 207 & 65 & 25 & Dwi Putrítutami & 216 & 75 \\
\hline 11 & Sartika & 220 & 79 & 26 & Eka Nurwahyuni & 231 & 94 \\
\hline 12 & Wiwik Oki Alla & 201 & 77 & 27 & Rotna Willis & 213 & 75 \\
\hline 13 & TrinNingsih & 224 & 77 & 28 & Nurul Hiddayatus S & 226 & 78 \\
\hline 14 & Sastra Arthhani & 229 & 84 & 29 & Ummi Anhh & 232 & 75 \\
\hline 15 & EviMunhlisah WN & 204 & 78 & 30 & M. Ansori & 210 & 83 \\
\hline
\end{tabular}

Dari analisis normalitas data hasil belajar mahasiswa pada Mata Kuliah Kalkulus Lanjut diperoleh $\chi_{\text {hitung }}^{2}=1,806$ dan $\chi_{\text {tabel }}^{2}=11,070 \quad$ dengan ketentuan $\chi_{\text {hitung }}^{2} \leq \chi_{\text {tabel }}^{2}$ maka Ho diterima dan $H_{1}$ ditolak. Sehingga diketahui bahwa data hasil belajar kalkulus lanjut berdistribusi normal. Kemudian dari hasil analisis normalitas data angket kemandirian belajar mahasiswa diperoleh $\chi_{\text {hitung }}^{2}=6,688$ dan $\chi_{\text {tabel }}^{2}=11,070$ dengan ketentuan $\chi_{\text {hitung }}^{2} \leq \chi_{\text {tabel }}^{2}$ maka Ho diterima dan $H_{1}$ ditolak. Sehingga diketahui bahwa data hasil angket kemandirian mahasiswa berdistribusi normal. Setelah diketahui semua data berdistribusi normal maka pengujian hipotesis dapat dilanjutkan dengan menggunakan Korelasi Pearson Product Moment. Berdasarkan analisis data dengan rumus Korelasi Pearson Product Moment, di peroleh hasil $r_{X Y}=0,566$ dengan interpretasi koefisien korelasi nilai $r$ masuk dalam tingkatan hubungan cukup kuat. Menyatakan besar kecilnya sumbang-an antara kemandirian belajar dan hasil belajar mahasiswa dengan rumus koefisien determinan diperoleh $K P=32,04 \%$. Pengujian lanjut yaitu uji signifikansi yang berfungsi untuk mencari makna antara kemandirian belajar dan hasil belajar mahasiswa, maka hasil Korelasi Pearson Product Moment tersebut diuji dengan uji signifikansi diperoleh $t_{\text {hitung }}=3,63$ yang hasilnya dibandingkan dengan $t_{\text {tabel }}$ dimana taraf signifikan $\quad(\alpha)=0,05 \quad(d k=n-2=$ $30-2=28)$ dan diperoleh $t_{\text {tabel }}=$ 1,701 . Kaidah pengujian karena $t_{\text {hitung }}>$ 
$t_{\text {tabel }}$ tolak $\mathrm{H}_{0}$ berarti ada hubungan kemandirian belajar dan hasil belajar mahasiswa pada Mata Kuliah Kalkulus Lanjut

Hal ini menunjukkan bahwa kemandirian belajar mahasiswa memiliki peran yang sangat penting dalam ketercapaian hasil belajar yang baik. Hal ini sejalan dengan pendapat Yamin (2013: 102) bahwa kemandirian belajar adalah cara belajar aktif dan partisipasif untuk mengembangkan diri masing-masing individu yang tidak terikat dengan kehadiran pembelajar, pertemuan tatap muka dikelas, dan kehadiran teman Sekolah. Kemandirian belajar merupakan sifat serta kemampuan yang dimiliki mahasiswa untuk melakukan kegiatan belajar aktif, yang didorong oleh motif untuk menguasai sesuatu kompetensi, dan dibangun dengan bekal pengetahuan atau kompetensi yang telah dimiliki untuk memanfaatkan dan mencari sumber yang relevan, memanfaatkan referensi sebagai penunjang pembelajaran serta mampu memanfaatkan konsep dirinya untuk mengembangkan kemampuan berpikirnya baik secara kreatif, kritis dan sistematis, seperti yang dikemukakan oleh Johnson (2011:158) menyatakan bahwa untuk menjadi mandiri, baik bekerja sendiri maupun kelompok, mahasiswa harus mengajukan pertanyaan menarik, membuat pilihan yang bertanggung jawab, berpikir kritis dan kreatif, memiliki pengetahuan tentang diri sendiri, dan bekerja sama, dimana kemandirian belajar sebagai suatu sistem belajar mandiri, merupakan sistem pembelajaran yang didasarkan kepada kedisiplinan terhadap diri sendiri yang dimiliki oleh mahasiswa disesuaikan oleh keadaan perorangan mahasiswa, waktu yang dimiliki dan keadaan sosial ekonominya.

Hal tersebut menunjukkan bahwa mahasiswa yang mandiri akan memberikan dampak hasil belajar yang optimal, mempunyai tanggung jawab, bekerja keras, motivasi tinggi, optimis, punya rasa ingin tahu yang besar, percaya diri, terbuka, memiliki toleransi serta memanfaat sumber belajar maupun referensi sebagai penunjang belajar. Terkhusus pada Mata Kuliah Kalkulus Lanjut. Mahasiswa tidak menjadi mahasiswa yang hanya menerima informasi dari dosen saja, tetapi mampu memanfaatkan waktu secara menyeluruh untuk belajar dan mengembangkan kemampuan berpikirnya dalam meng-hadapi sebuah permasalahan terkhusus masalah yang terkait dalam Mata Kuliah Kalkulus Lanjut. Oleh karena itu, dapat diketahui bahwa dalam penelitian ini terdapat hubungan kemandirian belajar mahasiswa terhadap hasil belajar pada Mata Kuliah Kalkulus Lanjut Tahun Akademik 20162017. 


\section{SIMPULAN}

Berdasarkan pada hasil analisis data bahwa pada Mata Kuliah Kalkulus Lanjut, dapat disimpulkan bahwa terdapat hubungan yang cukup kuat antara kemandirian belajar dengan hasil belajar mahasiswa semester 5 STKIP Muhammadiyah Pringsewu Lampung Program Studi Pendidikan Matematika pada Mata Kuliah Kalkulus Lanjut.

\section{DAFTAR PUSTAKA}

Suprijono, Agus. (2011). Cooperative Learning Teori dan Aplikasi PAIKEM. Yogyakarta: Pustaka Pelajar.

Sugandi, Asep Ikin. (2013). "Pengaruh Pembelajaran Berbasis Masalah dengan Setting Kooperatif Jigsaw terhadap Kemandirian Belajar Siswa SMA". Jurnal ilmiah Program Studi Matematika STKIP Siliwangi Bandung, Vol 2 (2).144-155.

Dimyati dan Mudjiono. (2009). Belajar dan pembelajaran. Bandung: Rieneka Cipta.

Johnson, Elaine B. (2011).Contextual Teaching and Learning: Menjadikan Kegiatan BelajarMengajar Mengasyikkan dan Bermakna. (diterjemahkan oleh A. Chaedar Alwasilah), Bandung: Mizan Learning Center.

Yamin, Martinis. (2013).Paradikma Baru Pembelajaran. Jakarta: Referensi.

Ali, Mohammad dan Asrori, Mohammad. (2011). Psikologi Remaja. Jakarta: Bumi Aksara.

Ratnaningsih, N. (2007). "Pengaruh Pembelajaran Kontekstual terhadap Kemampuan Berpikir Kritis dan Kreatif Matematik serta Kemandirian Belajar Siswa Sekolah Menengah Atas".Disertasi. UPI Bandung. Diakses: 20 Maret 2016.

Riduwan. (2009). Belajar Mudah Penelitian untuk Guru-Karyawan dan Peneliti Pemula. Bandung: Alfabeta.

Sugiono. (2010). Metode Penelitian Administrasi. Bandung: Alfabeta, cv. 